\title{
Dietary total antioxidant capacity from different assays in relation to serum C-reactive protein among young Japanese women
}

\author{
Satomi Kobayashi ${ }^{1}$, Kentaro Murakami ${ }^{2}$, Satoshi Sasaki ${ }^{1}{ }^{2}$, Kazuhiro Uenishi ${ }^{3}$, Mitsuyo Yamasaki ${ }^{4}$, \\ Hitomi Hayabuchi ${ }^{5}$, Toshinao Goda ${ }^{6}$, Jun Oka ${ }^{7}$, Keiko Baba ${ }^{8}$, Kazuko Ohki $^{9}$, Reiko Watanabe ${ }^{10}$ and \\ Yoshiko Sugiyamama ${ }^{11}$
}

\begin{abstract}
Background: The association between dietary total antioxidant capacity (TAC) from different assays and serum C-reactive protein (CRP) has not been assessed in non-Western populations. We examined the association between dietary TAC and serum CRP concentration in young Japanese women using different four TAC assays.

Methods: The subjects were 443 young Japanese women aged 18-22 years. Dietary TAC was assessed with a self-administered diet history questionnaire and the TAC value of each food using the following four assays: ferric reducing ability of plasma (FRAP); oxygen radical absorbance capacity (ORAC); Trolox equivalent antioxidant capacity (TEAC); and total radical-trapping antioxidant parameter (TRAP). Serum CRP concentrations were measured by highly sensitive nephelometry.

Results: The major contributor to dietary TAC was green, barley, and oolong tea (FRAP: 53\%, ORAC: 45\%, TEAC: 36\%, and TRAP: 44\%). The prevalence of elevated CRP concentrations ( $\geq 1 \mathrm{mg} / \mathrm{L}$ ) was $5.6 \%$. TAC from FRAP was inversely associated with serum CRP concentrations (adjusted odds ratio [OR] for elevated CRP concentration in high [compared with low] dietary TAC group: 0.39 [95\% confidence interval $(C \mathrm{Cl}): 0.16-0.98$ ]; $P=0.04$ ). TAC from ORAC was inversely associated with CRP, although the association was not significant (OR: 0.48 [95\% Cl: 0.20-1.14]; $P=0.10)$. TAC from TEAC was inversely associated with CRP (OR: 0.32 [95\% Cl: $0.12-0.82]$; $P=0.02)$, as was TAC from TRAP (OR: 0.31 [95\% Cl: 0.12-0.81]; $P=0.02$ ).
\end{abstract}

Conclusions: Dietary TAC was inversely associated with serum CRP concentration in young Japanese women regardless of assay. Further studies are needed in other populations to confirm these results.

Keywords: Dietary total antioxidant capacity, Serum C-reactive protein, Diet history questionnaire, Young Japanese women, Epidemiology

\section{Background}

C-reactive protein (CRP) is produced by hepatocytes as part of the acute-phase response and represents a sensitive and non-specific marker of inflammation [1]. CRP is associated with cardiovascular disease, type 2 diabetes mellitus, and cancer [2], and identification of the factors associated with serum CRP concentration is important

\footnotetext{
*Correspondence: stssasak@m.u-tokyo.ac.jp

'Department of Social and Preventive Epidemiology, Graduate School of Medicine, the University of Tokyo, Tokyo, Japan

${ }^{2}$ Department of Social and Preventive Epidemiology, School of Public Health, the University of Tokyo, 7-3-1 Hongo, Bunkyo-ku, Tokyo 113-0033, Japan Full list of author information is available at the end of the article
}

to their prevention. Dietary factors represent one major modifiable factor related to CRP, and several previous studies have shown that increasing the intake of antioxidant nutrients (e.g., vitamin $\mathrm{C}$ and vitamin $\mathrm{E}$ ) or foods (e.g., tea, fruits, and vegetables) is associated with decreased CRP concentrations [2-4]. In other studies, however, these single nutrients or foods were shown to have no effect [2,5-7]. Accumulating mechanistic and epidemiological data suggest that antioxidants act not only individually but also co-operatively, and in some cases synergistically [8]. The effect of complex combinations of 
antioxidant nutrients and foods on CRP concentrations therefore warrants investigation.

Recently, the concept of dietary total antioxidant capacity (TAC) was proposed to assess the combined effect of multiple antioxidants [9]. Previous observational studies [10-12] and an interventional study [13] showed that dietary TAC was inversely related to CRP among Italian, Spanish, and Greek populations. Given that dietary habits vary by country - vegetables commonly consumed in Japan differ from those consumed in Italy, for example $[14,15]$ - the food source of dietary TAC at the intake level may also differ, and the association should therefore be evaluated in other countries, including Japan. Further, because CRP concentration tends to increase with age [16], maintaining concentrations as low as possible in younger age is an important preventive measure. Evaluation of the association between dietary TAC and CRP among young adult populations is therefore important.

Here, we estimated dietary TAC from different assays in young Japanese women and examined the association between dietary TAC and serum CRP concentration using these assays.

\section{Methods}

\section{Study population}

Details of the study population have been reported elsewhere [5]. Briefly, the present study was based on a multi-center survey conducted from February to March 2006 among female dietetic students from 10 institutions in Japan. The study protocol was approved by the Ethics Committee of the National Institutes of Health and Nutrition, and written informed consent was obtained from each subject, and also from a parent for subjects aged less than 20 years. A total of 474 women took part. We excluded subjects whose CRP concentrations had not been measured $(n=22)$, those with CRP concentrations $\geq 10 \mathrm{mg} / \mathrm{L}(\mathrm{n}=2)$ on the basis that such high concentrations were likely caused by infection or an underlying medical problem not related to diet [17], and those aged $<18$ or $\geq 23$ years $(n=7)$. The final sample thus comprised 443 women aged 18-22 years. All women were free from diabetes, hypertension, and cardiovascular disease, and none reported extremely low (less than half the energy requirement for the lowest physical activity category $(<775(1550 \times 0.5) \mathrm{kcal} /$ day $))$ or high (more than 1.5 times the energy requirement of the highest physical activity category $(>3450(2300 \times 1.5)$ $\mathrm{kcal} /$ day)) energy intake with reference to the Recommended Dietary Allowance for Japanese [5,18,19].

\section{Dietary assessment}

Dietary habits during the preceding month were assessed using a previously validated, self-administered comprehensive diet history questionnaire (DHQ) [20,21]. Responses to the DHQ as well as to an accompanying lifestyle questionnaire were checked at least twice for completeness, and reviewed with the subject when necessary to ensure the clarity of answers. Estimates of dietary intake for a total of 150 food items, energy, and n-3 polyunsaturated fatty acid (PUFA) were calculated using an ad hoc computer algorithm for the DHQ based on the Standard Tables of Food Composition in Japan [22]. Although dietary supplement use was queried in the DHQ, intake from supplements was not included in analyses due to the lack of a reliable composition table of dietary supplements in Japan.

\section{Estimation of dietary TAC}

To calculate dietary TAC, a TAC value was assigned to each food item in the DHQ. Among the 150 food items in the DHQ, 54 foods were determined to contain no TAC value because they contained no or only trace amount of antioxidant nutrients such as carotenes, vitamin C, or vitamin E (e.g., animal foods and refined foods). We therefore searched for the analytical TAC value of the remaining 96 foods in the DHQ using the following four assays: ferric reducing ability of plasma (FRAP); oxygen radical absorbance capacity (ORAC); Trolox equivalent antioxidant capacity (TEAC); and total radical-trapping antioxidant parameter (TRAP).

Studies reporting the analytical TAC value of foods were identified by searching the PubMed database, which resulted in many TAC values for assignment to specific foods (about $70 \%$ of 96 foods). If we could not obtain a TAC value from PubMed, we searched the database of one journal, Food Chemistry, which was frequently referred to in the papers obtained from the PubMed search. The TAC values of four foods for ORAC and 11 foods for TEAC were obtained from this journal database only [23-28]. We therefore used papers in the literature reporting TAC values of food in analytical data for FRAP [15,29-34], ORAC [14,23,24,35-45], TEAC [15,25-28,33,46-49], and TRAP [15,33]. TAC values were expressed as mmol $\mathrm{Fe}^{2+} / 100 \mathrm{~g}$ of food for FRAP or as mmol of Trolox equivalent (mmol TE)/ $100 \mathrm{~g}$ of food for ORAC, TEAC, and TRAP.

When the analytical TAC value for a specific food could be obtained, the mean TAC value was calculated by weighting the number of foods analyzed in each study, and the mean value was assigned (analytical value; FRAP: $n=40$, ORAC: $n=23$, TEAC: $n=22$, and TRAP: $\mathrm{n}=21$ ). When the analytical TAC value for a specific food could not be obtained, the mean value of similar foods or a different form of the same food was assigned (substituted value; FRAP: $\mathrm{n}=22$, ORAC: $\mathrm{n}=20$, TEAC: $n=22$, and TRAP: $n=20$ ). For fresh foods, if the TAC value of the food was obtained in dry matter only, the 
Table 1 TAC values of food items included in the diet history questionnaire and the contribution (\%) of dietary TAC among 443 Japanese women aged 18-22 years

\begin{tabular}{|c|c|c|c|c|c|c|c|c|c|c|c|c|}
\hline \multirow[t]{2}{*}{ Food group and item†‡ } & \multicolumn{3}{|c|}{ FRAP } & \multicolumn{3}{|c|}{ ORAC } & \multicolumn{3}{|c|}{ TEAC } & \multicolumn{3}{|c|}{ TRAP } \\
\hline & $\begin{array}{r}\mathrm{TAC}^{2+} \\
(\mathrm{mmol} \mathrm{Fe} \\
\end{array}$ & $100 \mathrm{~g})$ & $\begin{array}{l}\text { Contribution* } \\
(\%)\end{array}$ & $\begin{array}{r}\text { TAC } \\
\text { (mmol TE/ }\end{array}$ & $100 \mathrm{~g})$ & $\begin{array}{c}\text { Contribution* } \\
(\%)\end{array}$ & $\begin{array}{r}\text { TAC } \\
(\mathrm{mmol} \mathrm{TE} / \\
\end{array}$ & $100 \mathrm{~g})$ & $\begin{array}{l}\text { Contribution* } \\
(\%)\end{array}$ & $\begin{array}{r}\text { TAC } \\
(\mathrm{mmol} \mathrm{TE} / 1 \\
\end{array}$ & $00 \mathrm{~g})$ & $\begin{array}{c}\text { Contribution* } \\
(\%)\end{array}$ \\
\hline Non-alcoholic beverages & - & & $77.77(66.79-85.02)$ & - & & $67.18(55.23-77.39)$ & - & & $63.66(51.56-74.41)$ & - & & $77.65(66.16-85.78)$ \\
\hline $\begin{array}{l}\text { Green, barley, and oolong tea } \\
\text { (including other Chinese tea) }\end{array}$ & 1.41 & $\|$ & $57.31(36.17-73.16)$ & 1.86 & 9 & $46.97(28.17-63.41)$ & 0.54 & $\|$ & $36.75(19.33-52.92)$ & 0.69 & $\|$ & $46.47(23.16-65.41)$ \\
\hline Coffee & 3.23 & $\S$ & $3.16(0.00-17.16)$ & 4.24 & $\S$ & $2.68(0.00-14.91)$ & 3.14 & $\S$ & $6.22(0.00-27.48)$ & 5.60 & $\S$ & $10.15(0.00-41.59)$ \\
\hline Black tea & 0.97 & $\S$ & $0.00(0.00-5.20)$ & 1.48 & 9 & $0.00(0.00-4.74)$ & 0.36 & $\S$ & $0.00(0.00-3.08)$ & 0.49 & $\S$ & $0.00(0.00-4.07)$ \\
\hline Cocoa & 0.80 & $\S$ & $0.00(0.00-1.70)$ & 3.03 & 9 & $0.00(0.00-4.07)$ & 1.41 & 9 & $0.00(0.00-5.40)$ & 0.45 & १ & $0.00(0.00-1.68)$ \\
\hline Fruit juice (100\%) & 0.62 & $\|$ & $0.00(0.00-0.94)$ & 0.64 & $\|$ & $0.00(0.00-0.62)$ & 0.27 & $\|$ & $0.00(0.00-0.63)$ & 0.23 & $\|$ & $0.00(0.00-0.45)$ \\
\hline Vegetable juice & 0.38 & $\|$ & $0.00(0.00-0.85)$ & 0.48 & $\S$ & $0.00(0.00-0.62)$ & 0.17 & $\|$ & $0.00(0.00-0.61)$ & 0.16 & $\|$ & $0.00(0.00-0.55)$ \\
\hline Tomato juice & 0.48 & $\S$ & $0.00(0.00-0.00)$ & 0.43 & $\S$ & $0.00(0.00-0.00)$ & 0.17 & $\|$ & $0.00(0.00-0.00)$ & 0.13 & $\|$ & $0.00(0.00-0.00)$ \\
\hline Fruit juice, excluding $100 \%$ juice & 0.31 & १ & $0.00(0.00-0.00)$ & 0.32 & 9 & $0.00(0.00-0.00)$ & 0.14 & १ & $0.00(0.00-0.00)$ & 0.11 & १ & $0.00(0.00-0.00)$ \\
\hline Vegetables & - & & $7.50(4.56-12.13)$ & - & & $11.13(7.29-16.19)$ & - & & $8.61(5.41-12.65)$ & - & & $8.29(5.11-13.38)$ \\
\hline Green leafy vegetables & 1.08 & $\|$ & $2.27(1.03-4.23)$ & 1.53 & $\|$ & $2.02(0.95-3.72)$ & 0.69 & $\|$ & $2.28(1.18-4.56)$ & 0.48 & $\|$ & $1.50(0.75-3.15)$ \\
\hline Cabbage & 0.45 & $\S$ & $0.69(0.30-1.19)$ & 0.52 & $\|$ & $0.50(0.22-0.85)$ & 0.12 & $\|$ & $0.30(0.13-0.54)$ & 0.28 & $\|$ & $0.66(0.29-1.25)$ \\
\hline Chinese cabbage & 0.45 & $\|$ & $0.46(0.22-1.09)$ & 0.52 & $\|$ & $0.33(0.17-0.76)$ & 0.12 & $\|$ & $0.21(0.11-0.46)$ & 0.28 & $\|$ & $0.44(0.22-1.14)$ \\
\hline Broccoli & 0.96 & $\S$ & $0.45(0.20-1.18)$ & 1.48 & $\|$ & $0.45(0.21-1.13)$ & 0.30 & $\|$ & $0.24(0.11-0.61)$ & 0.31 & $\|$ & $0.25(0.09-0.61)$ \\
\hline Onions & 0.29 & $\S$ & $0.37(0.19-0.70)$ & 1.22 & $\|$ & $0.99(0.52-1.78)$ & 0.18 & $\|$ & $0.39(0.19-0.71)$ & 0.24 & $\|$ & $0.49(0.24-0.94)$ \\
\hline Radishes & 0.31 & $\|$ & $0.30(0.15-0.61)$ & 1.50 & $\|$ & $0.91(0.47-1.81)$ & 0.55 & $\|$ & $0.86(0.47-1.73)$ & 0.66 & $\|$ & $0.99(0.50-2.05)$ \\
\hline Green peppers & 1.02 & $\S$ & $0.24(0.10-0.48)$ & 0.93 & $\S$ & $0.14(0.06-0.27)$ & 0.84 & $\|$ & $0.34(0.13-0.64)$ & 0.55 & $\|$ & $0.21(0.07-0.40)$ \\
\hline Mushrooms & 0.22 & $\|$ & $0.19(0.09-0.35)$ & 0.65 & $\|$ & $0.35(0.16-0.63)$ & 0.49 & $\|$ & $0.70(0.33-1.29)$ & 0.63 & $\|$ & $0.88(0.39-1.55)$ \\
\hline Tomatoes & 0.27 & $\S$ & $0.18(0.08-0.40)$ & 0.39 & $\S$ & $0.16(0.07-0.37)$ & 0.17 & $\S$ & $0.18(0.08-0.39)$ & 0.13 & $\S$ & $0.14(0.05-0.31)$ \\
\hline Lotus root & 1.58 & $\|$ & $0.17(0.00-0.36)$ & 2.10 & $\|$ & $0.14(0.00-0.31)$ & - & & - & - & & - \\
\hline Lettuce & 0.27 & $\S$ & $0.11(0.04-0.26)$ & 0.32 & $\S$ & $0.08(0.03-0.20)$ & 0.13 & $\S$ & $0.08(0.04-0.20)$ & 0.23 & $\S$ & $0.14(0.05-0.37)$ \\
\hline Carrots & 0.10 & $\|$ & $0.10(0.05-0.20)$ & 0.33 & $\|$ & $0.21(0.11-0.40)$ & 0.04 & $\|$ & $0.07(0.03-0.12)$ & 0.07 & $\|$ & $0.12(0.05-0.20)$ \\
\hline Other salted pickles & 0.36 & 9 & $0.09(0.03-0.27)$ & 1.29 & 9 & $0.21(0.07-0.58)$ & 0.31 & 9 & $0.13(0.05-0.35)$ & 0.45 & १ & $0.18(0.06-0.52)$ \\
\hline Pumpkins & 0.11 & $\|$ & $0.04(0.02-0.08)$ & 0.48 & $\|$ & $0.12(0.04-0.23)$ & 0.37 & $\|$ & $0.24(0.09-0.46)$ & 0.00 & $\|$ & $0.00(0.00-0.00)$ \\
\hline Eggplants & 0.18 & $\|$ & $0.03(0.00-0.09)$ & 0.25 & $\|$ & $0.02(0.00-0.07)$ & 0.11 & $\|$ & $0.03(0.00-0.09)$ & 0.28 & $\|$ & $0.06(0.00-0.21)$ \\
\hline Cucumbers & 0.05 & $\S$ & $0.01(0.01-0.04)$ & 0.21 & $\S$ & $0.04(0.01-0.09)$ & 0.04 & $\S$ & $0.02(0.01-0.05)$ & 0.00 & $\S$ & $0.00(0.00-0.00)$ \\
\hline Salted pickled plums & 0.45 & $\|$ & $0.01(0.00-0.04)$ & 3.62 & 9 & $0.07(0.00-0.22)$ & 0.47 & 9 & $0.03(0.00-0.08)$ & 0.75 & १ & $0.04(0.00-0.12)$ \\
\hline Cauliflower & 0.80 & $\S$ & $0.00(0.00-0.00)$ & 0.85 & $\|$ & $0.00(0.00-0.00)$ & 0.11 & $\|$ & $0.00(0.00-0.00)$ & 0.16 & $\|$ & $0.00(0.00-0.00)$ \\
\hline
\end{tabular}


Table 1 TAC values of food items included in the diet history questionnaire and the contribution (\%) of dietary TAC among 443 Japanese women aged 18-22 years (Continued)

\begin{tabular}{|c|c|c|c|c|c|c|c|c|c|c|c|c|}
\hline Burdock & - & & - & 5.22 & $\|$ & $0.87(0.39-1.45)$ & - & & - & - & & - \\
\hline Bean sprouts & - & & - & 1.72 & $\|$ & $0.38(0.19-0.88)$ & 0.15 & $\|$ & $0.09(0.04-0.20)$ & - & & - \\
\hline Wakame and hijiki seaweed & - & & - & 0.45 & 9 & $0.21(0.10-0.40)$ & 0.15 & 9 & $0.18(0.09-0.35)$ & - & & - \\
\hline Laver (dried, edible seaweed) & - & & - & 6.11 & $\|$ & $0.03(0.02-0.08)$ & 2.30 & $\|$ & $0.03(0.02-0.08)$ & - & & - \\
\hline Fruits & - & & $3.67(1.75-6.55)$ & - & & $5.92(3.05-10.17)$ & - & & $3.12(1.42-5.89)$ & - & & $2.49(1.10-4.40)$ \\
\hline Oranges & 0.87 & $\|$ & $1.01(0.36-2.62)$ & 1.74 & $\|$ & $1.26(0.47-3.15)$ & 0.31 & $\|$ & $0.59(0.22-1.46)$ & 0.36 & $\|$ & $0.65(0.23-1.67)$ \\
\hline Strawberries & 2.16 & $\S$ & $0.97(0.26-2.10)$ & 3.67 & $\S$ & $1.03(0.30-2.20)$ & 1.69 & $\S$ & $1.26(0.32-2.59)$ & 0.86 & $\S$ & $0.60(0.12-1.35)$ \\
\hline Apples & 0.39 & $\S$ & $0.25(0.06-0.69)$ & 2.80 & $\S$ & $1.18(0.30-2.89)$ & 0.15 & $\S$ & $0.17(0.04-0.40)$ & 0.19 & $\S$ & $0.19(0.04-0.51)$ \\
\hline Bananas & 0.19 & $\S$ & $0.08(0.00-0.21)$ & 0.74 & $\S$ & $0.21(0.00-0.52)$ & 0.06 & $\S$ & $0.04(0.00-0.11)$ & 0.11 & $\S$ & $0.07(0.00-0.20)$ \\
\hline Kiwi fruits & 0.95 & $\S$ & $0.00(0.00-0.30)$ & 0.83 & $\S$ & $0.00(0.00-0.17)$ & 0.23 & $\S$ & $0.00(0.00-0.12)$ & 0.23 & $\S$ & $0.00(0.00-0.10)$ \\
\hline Canned fruits & 0.42 & १ & $0.00(0.00-0.08)$ & 1.32 & 9 & $0.00(0.00-0.17)$ & 0.19 & 9 & $0.00(0.00-0.07)$ & 0.22 & 9 & $0.00(0.00-0.07)$ \\
\hline Raisins & 1.28 & $\S$ & $0.00(0.00-0.07)$ & 5.75 & $\S$ & $0.00(0.00-0.20)$ & 0.66 & $\S$ & $0.00(0.00-0.06)$ & 0.62 & $\S$ & $0.00(0.00-0.04)$ \\
\hline Grapes & 0.78 & $\S$ & $0.00(0.00-0.00)$ & 1.29 & $\S$ & $0.00(0.00-0.00)$ & 0.32 & $\S$ & $0.00(0.00-0.00)$ & 0.20 & $\S$ & $0.00(0.00-0.00)$ \\
\hline Persimmons & 0.49 & $\S$ & $0.00(0.00-0.00)$ & 0.74 & $\S$ & $0.00(0.00-0.00)$ & 6.86 & 9 & $0.00(0.00-0.00)$ & - & & - \\
\hline Peaches & 0.24 & $\S$ & $0.00(0.00-0.00)$ & 1.92 & $\S$ & $0.00(0.00-0.00)$ & 0.17 & $\S$ & $0.00(0.00-0.00)$ & 0.15 & $\S$ & $0.00(0.00-0.00)$ \\
\hline Pears & 0.22 & $\|$ & $0.00(0.00-0.00)$ & 1.80 & $\|$ & $0.00(0.00-0.00)$ & 0.22 & $\|$ & $0.00(0.00-0.00)$ & 0.39 & $\|$ & $0.00(0.00-0.00)$ \\
\hline Melons & 0.18 & $\S$ & $0.00(0.00-0.00)$ & 0.24 & $\S$ & $0.00(0.00-0.00)$ & 0.09 & $\S$ & $0.00(0.00-0.00)$ & 0.10 & $\S$ & $0.00(0.00-0.00)$ \\
\hline Watermelons & 0.05 & $\S$ & $0.00(0.00-0.00)$ & 0.17 & $\S$ & $0.00(0.00-0.00)$ & 0.07 & $\S$ & $0.00(0.00-0.00)$ & 0.05 & $\S$ & $0.00(0.00-0.00)$ \\
\hline Sugar and confectioneries & - & & $2.58(1.38-5.58)$ & - & & $2.94(1.56-6.00)$ & - & & $3.73(2.02-7.63)$ & - & & $1.11(0.56-2.55)$ \\
\hline Chocolate & 3.96 & $\S$ & $1.94(0.98-4.63)$ & 7.16 & $\S$ & $2.26(1.13-5.28)$ & 3.62 & $\S$ & $3.06(1.54-6.83)$ & 1.16 & $\S$ & $0.93(0.42-2.33)$ \\
\hline Cookies and biscuits & 0.42 & $\|$ & $0.11(0.05-0.24)$ & - & & - & - & & - & - & & - \\
\hline Japanese sweets with azuki beans & 0.54 & १ & $0.09(0.03-0.16)$ & 0.42 & 9 & $0.04(0.01-0.08)$ & 0.29 & १ & $0.08(0.02-0.14)$ & 0.18 & १ & $0.05(0.01-0.09)$ \\
\hline Jam and marmalade & 0.71 & १ & $0.04(0.00-0.13)$ & 1.57 & 9 & $0.05(0.00-0.18)$ & 0.40 & १ & $0.03(0.00-0.13)$ & 0.25 & 9 & $0.02(0.00-0.08)$ \\
\hline Potato chips & 0.59 & $\S$ & $0.04(0.00-0.09)$ & 2.09 & 9 & $0.09(0.00-0.21)$ & 0.25 & 9 & $0.03(0.00-0.07)$ & 0.26 & 9 & $0.02(0.00-0.07)$ \\
\hline Japanese bread with a sweet filling & 0.03 & १ & $0.03(0.01-0.07)$ & 0.25 & १ & $0.18(0.07-0.36)$ & 0.13 & 9 & $0.24(0.10-0.47)$ & - & & - \\
\hline Doughnuts & 0.15 & $\|$ & $0.00(0.00-0.09)$ & - & & - & - & & - & - & & - \\
\hline Pancakes & 0.15 & $\|$ & $0.00(0.00-0.02)$ & - & & - & - & & - & - & & - \\
\hline Jellies & 0.01 & $\|$ & $0.00(0.00-0.01)$ & - & & - & - & & - & - & & - \\
\hline Cereals & - & & $1.63(0.96-3.33)$ & - & & $1.21(0.41-3.00)$ & - & & $4.88(3.25-7.86)$ & - & & $7.34(4.22-12.05)$ \\
\hline Well-milled rice & 0.02 & $\S$ & $0.38(0.20-0.68)$ & - & & & 0.10 & १ & $3.21(1.60-5.50)$ & 0.18 & 9 & $5.36(2.39-10.26)$ \\
\hline White bread & 0.20 & $\S$ & $0.31(0.16-0.67)$ & - & & - & - & & - & - & & - \\
\hline
\end{tabular}


Table 1 TAC values of food items included in the diet history questionnaire and the contribution (\%) of dietary TAC among 443 Japanese women aged 18-22 years (Continued)

\begin{tabular}{|c|c|c|c|c|c|c|c|c|c|c|c|c|}
\hline $\begin{array}{l}\text { Japanese noodles (buckwheat and } \\
\text { Japanese wheat noodles) }\end{array}$ & 0.12 & 9 & $0.18(0.04-0.38)$ & 0.65 & १ & $0.62(0.14-1.31)$ & 0.19 & 9 & $0.49(0.11-1.00)$ & 0.12 & 9 & $0.28(0.05-0.63)$ \\
\hline Spaghetti & 0.03 & $\S$ & $0.05(0.02-0.11)$ & - & & - & 0.08 & 9 & $0.22(0.07-0.46)$ & 0.06 & 9 & $0.15(0.05-0.36)$ \\
\hline Pizza & 0.20 & $\S$ & $0.00(0.00-0.15)$ & - & & - & - & & - & - & & - \\
\hline Cornflakes & 0.93 & $\S$ & $0.00(0.00-0.00)$ & 2.36 & $\S$ & $0.00(0.00-0.00)$ & 0.22 & $\S$ & $0.00(0.00-0.00)$ & 0.18 & $\S$ & $0.00(0.00-0.00)$ \\
\hline Brown rice & 0.27 & $\S$ & $0.00(0.00-0.00)$ & 1.14 & १ & $0.00(0.00-0.00)$ & 0.18 & 9 & $0.00(0.00-0.00)$ & 0.22 & 9 & $0.00(0.00-0.00)$ \\
\hline Half-milled rice & 0.21 & 9 & $0.00(0.00-0.00)$ & 0.60 & १ & $0.00(0.00-0.00)$ & 0.14 & 9 & $0.00(0.00-0.00)$ & 0.20 & 9 & $0.00(0.00-0.00)$ \\
\hline Well-milled rice mixed with barley & 0.15 & १ & $0.00(0.00-0.00)$ & 0.39 & १ & $0.00(0.00-0.00)$ & 0.10 & 9 & $0.00(0.00-0.00)$ & 0.14 & १ & $0.00(0.00-0.00)$ \\
\hline $70 \%$ milled rice & 0.13 & १ & $0.00(0.00-0.00)$ & 0.25 & १ & $0.00(0.00-0.00)$ & 0.12 & 9 & $0.00(0.00-0.00)$ & 0.18 & 9 & $0.00(0.00-0.00)$ \\
\hline Well-milled rice with germ & 0.10 & 9 & $0.00(0.00-0.00)$ & 0.13 & १ & $0.00(0.00-0.00)$ & 0.11 & 9 & $0.00(0.00-0.00)$ & 0.18 & 9 & $0.00(0.00-0.00)$ \\
\hline Oils & - & & $0.98(0.56-1.62)$ & - & & - & - & & $0.36(0.24-0.53)$ & - & & - \\
\hline Oil used during cooking & 0.44 & 9 & $0.43(0.28-0.65)$ & - & & - & 0.22 & $\|$ & $0.36(0.24-0.53)$ & - & & - \\
\hline Mayonnaise & 1.08 & $\S$ & $0.26(0.00-0.62)$ & - & & - & - & & - & - & & - \\
\hline Margarine & 1.05 & $\S$ & $0.05(0.00-0.16)$ & - & & - & - & & - & - & & - \\
\hline Salad dressing & 0.25 & $\S$ & $0.05(0.00-0.16)$ & - & & - & - & & - & - & & - \\
\hline Nuts and pulses & - & & $0.93(0.53-1.65)$ & - & & $3.49(2.11-5.97)$ & - & & $7.70(4.49-12.55)$ & - & & $0.07(0.00-0.21)$ \\
\hline Natto (fermented soybeans) & 0.40 & 9 & $0.22(0.07-0.69)$ & 2.27 & १ & $0.82(0.28-2.50)$ & 2.05 & 9 & $2.02(0.61-5.81)$ & - & & - \\
\hline Tofu (soybean curd) & 0.09 & $\|$ & $0.12(0.05-0.25)$ & 0.79 & १ & $0.66(0.30-1.42)$ & 0.71 & 9 & $1.55(0.69-3.37)$ & - & & - \\
\hline Miso for miso soup & 0.31 & 9 & $0.12(0.04-0.23)$ & 1.72 & १ & $0.43(0.16-0.77)$ & 1.55 & 9 & $1.03(0.33-1.94)$ & - & & - \\
\hline Boiled beans & 0.34 & १ & $0.06(0.00-0.13)$ & 2.09 & १ & $0.23(0.00-0.49)$ & 0.96 & 9 & $0.28(0.00-0.62)$ & - & & - \\
\hline Tofu (soybean curd) products & 0.36 & 9 & $0.00(0.00-0.13)$ & 2.05 & १ & $0.00(0.00-0.47)$ & 1.85 & 9 & $0.00(0.00-1.13)$ & - & & - \\
\hline Peanuts & 1.20 & $\S$ & $0.00(0.00-0.10)$ & 3.17 & $\S$ & $0.00(0.00-0.17)$ & 0.48 & $\S$ & $0.00(0.00-0.07)$ & 0.33 & $\S$ & $0.00(0.00-0.05)$ \\
\hline Other nuts & 0.84 & $\|$ & $0.00(0.00-0.08)$ & 4.69 & $\|$ & $0.00(0.00-0.27)$ & 4.76 & 9 & $0.00(0.00-0.71)$ & 1.08 & $\|$ & $0.00(0.00-0.16)$ \\
\hline Miso as seasoning & 0.31 & 9 & $0.00(0.00-0.00)$ & 1.72 & १ & $0.00(0.00-0.00)$ & 1.55 & 9 & $0.00(0.00-0.00)$ & - & & - \\
\hline Seasonings & - & & $0.79(0.42-1.30)$ & - & & $0.33(0.19-0.53)$ & - & & $0.74(0.42-1.14)$ & - & & $0.00(0.00-0.04)$ \\
\hline Soy sauce & 1.68 & $\|$ & $0.75(0.39-1.25)$ & 1.06 & १ & $0.31(0.17-0.48)$ & 0.96 & 9 & $0.71(0.40-1.12)$ & - & & - \\
\hline Tomato ketchup & 0.37 & $\S$ & $0.00(0.00-0.06)$ & 0.58 & $\S$ & $0.00(0.00-0.05)$ & 0.15 & $\|$ & $0.00(0.00-0.04)$ & 0.17 & $\|$ & $0.00(0.00-0.04)$ \\
\hline Potatoes & - & & $0.40(0.22-0.73)$ & - & & $1.30(0.73-2.28)$ & - & & $0.36(0.19-0.63)$ & - & & $0.24(0.11-0.48)$ \\
\hline Sweet potatoes, yams, and taro & 0.21 & $\|$ & $0.13(0.07-0.27)$ & 1.08 & $\|$ & $0.43(0.22-0.86)$ & 0.09 & $\S$ & $0.09(0.05-0.18)$ & - & & - \\
\hline Potatoes & 0.13 & $\S$ & $0.13(0.06-0.28)$ & 0.67 & $\S$ & $0.42(0.21-0.89)$ & 0.08 & $\S$ & $0.13(0.07-0.28)$ & 0.09 & $\S$ & $0.00(0.06-0.33)$ \\
\hline French fries & 0.26 & $\S$ & $0.06(0.00-0.13)$ & 1.24 & १ & $0.17(0.00-0.39)$ & 0.15 & १ & $0.05(0.00-0.12)$ & 0.16 & १ & $0.05(0.00-0.13)$ \\
\hline Konnyaku (devil's tongue jelly) & 0.04 & 9 & $0.01(0.00-0.01)$ & 0.20 & १ & $0.03(0.01-0.04)$ & 0.01 & 9 & $0.00(0.00-0.01)$ & - & & - \\
\hline
\end{tabular}


Table 1 TAC values of food items included in the diet history questionnaire and the contribution (\%) of dietary TAC among 443 Japanese women aged 18-22 years (Continued)

\begin{tabular}{lcccccccccccccc}
\hline Alcoholic beverages & - & & $0.00(0.00-0.00)$ & - & & $0.00(0.00-0.00)$ & - & $0.00(0.00-0.00)$ & - & $0.00(0.00-0.00)$ \\
Wine & 1.41 & $\S$ & $0.00(0.00-0.00)$ & 1.17 & $\S$ & $0.00(0.00-0.00)$ & 0.63 & $\S$ & $0.00(0.00-0.00)$ & 0.82 & $\S$ & $0.00(0.00-0.00)$ \\
Whiskey & 0.25 & $\S$ & $0.00(0.00-0.00)$ & - & & - & 0.15 & $\S$ & $0.00(0.00-0.00)$ & 0.19 & $\S$ & $0.00(0.00-0.00)$ \\
Beer & 0.24 & $\S$ & $0.00(0.00-0.00)$ & - & - & & 0.10 & $\S$ & $0.00(0.00-0.00)$ & 0.00 & $\S$ & $0.00(0.00-0.00)$ \\
\hline
\end{tabular}

TAC total antioxidant capacity, FRAP ferric reducing ability of plasma, ORAC oxygen radical absorbance capacity, TEAC Trolox equivalent antioxidant capacity,

TRAP total radical-trapping antioxidant parameter, TE Trolox equivalent.

* Values are medians (interquartile ranges).

† These 84 food items from the 150 items in the diet history questionnaire were used in the present study. Among the remaining 66 food items, the following 54 were determined to contain no TAC value: all 15 items in fish and shellfish (dried fish; small fish with bones; canned tuna; eel; white meat fish; oily fish; red meat fish; ground fish meat products; shrimp and crab; squid and octopus; oysters: other shellfish; fish eggs; boiled fish and shellfish in soy sauce; and salted fish intestines); all 7 items in meat (ground beef and pork; chicken; pork; beef; liver; ham and sausages; and bacon); all 9 items in dairy products (full-fat milk; low-fat milk; skim milk; sweetened yogurt; nonsweetened yogurt; moderately sweetened yogurt; cheese; cottage cheese; and cream or creamer added to coffee); 5 items in other animal foods (ice cream [regular]; ice cream [premium]; ice cream [unspecified varieties]; butter; and eggs); and 18 items in other foods (sugar for coffee and black tea; sugar used during cooking; artificial sweeteners; candies, caramels, and chewing gum; non-oil dressings; table salt; salt used during cooking; corn soup; Chinese soup; soup consumed with noodles; water for miso soup; sake; shochu; shochu mixed with water or a carbonated beverage; lactic acid bacteria beverages; cola and sugar-sweetened soft drinks [including sports drinks]; sugar-free soft drinks and diet cola; and drinking water. The following 12 items could not assigned a TAC value for all four methods: instant noodles; Chinese noodles; butter roll; croissant; Japanese-style pancakes; rice crackers; snacks made from wheat flour; Japanese sweets without azuki beans; cakes; curry or stew roux and meat sauce; nutritional supplement drinks; and nutritional supplement bars.

\# Food items were categorized into food groups according to our previous study [20]. Tomato ketchup and soy sauce were included in seasonings. Food groups and food items were listed in descending order F Food items were categorized into food groups according to our previous study [20. Tomat ketchup and soy sauce were included in seasonings. Food

according to the contribution to FRAP. Four

§ TAC value was assigned an analytical value.

\| TAC value was assigned a substituted value.
I TAC value was assigned a calculated value. 
TAC value was calculated using the dry matter value and the proportion of water in the fresh food. For processed foods, if we obtained the TAC values of the ingredient foods, TAC values were calculated by the values of the ingredient foods and their proportion of the total food component. When we obtained a TAC value by these calculations, this value was assigned (calculated value; FRAP: $n=18$, ORAC: $n=27$, TEAC: $n=29$, and TRAP: $n=17$ ). The remaining foods were not assigned a TAC value because no value could be assigned using any of the above steps (FRAP: $n=16$, ORAC: $n=26$, TEAC: $\mathrm{n}=23$, and TRAP: $\mathrm{n}=38$ ). Of the 96 foods for which TAC values were sought, 12 could not be assigned a value by any of the four methods. Values for the remaining 84 food items used to calculate dietary TAC in this study are presented in Table 1. Dietary TAC was estimated based on intake and the TAC value of each food.

\section{Serum CRP concentrations}

Peripheral blood samples were obtained from subjects after an overnight fast. Blood was collected in evacuated tubes containing no additives, allowed to clot, and centrifuged at $3000 \times g$ for $10 \mathrm{~min}$ at room temperature to separate serum. Blood samples were transported at $-20^{\circ} \mathrm{C}$ to a laboratory (SRL Inc, Tokyo, Japan). Serum CRP concentrations were measured by highly sensitive nephelometry at SRL Inc. In-house quality-control procedures were fulfilled at SRL Inc, and showed within- and between-assay coefficients of variation of $3.1 \%$ and $2.7 \%$, respectively. The assay is sufficiently sensitive to detect $0.050 \mathrm{mg} / \mathrm{L}$. Undetectable CRP values were recorded as $0.025 \mathrm{mg} / \mathrm{L}$ $(\mathrm{n}=81)$. Serum CRP concentrations $\geq 1 \mathrm{mg} / \mathrm{L}$ were considered elevated for several reasons. First, previous studies have consistently shown that the median serum CRP concentration in Japanese $(0.09-0.58 \mathrm{mg} / \mathrm{mL})$ was lower than those in Western populations $(1.5-6.2 \mathrm{mg} / \mathrm{mL})$ $[50,51]$. Therefore to use cutoff value mainly based on Western population [17] might not be appropriate. Second, a higher serum CRP concentration is unfavorable for Japanese, although this value was not as high as those of other countries [50]. Third, because CRP concentration tends to increase with age [16], maintaining CRP concentrations as low as possible in younger age is an important preventive measure. Fourth, some previous Japanese studies used $1 \mathrm{mg} / \mathrm{L}$ of serum CRP concentration as cut off value $[5,51]$.

\section{Other variables}

Body height was measured to the nearest $0.1 \mathrm{~cm}$ with the subject standing without shoes. Body weight in light indoor clothes was measured to the nearest $0.1 \mathrm{~kg}$. Body mass index (BMI) was calculated as body weight (kilograms) divided by the square of body height (meters). In the lifestyle questionnaire, the subject reported her residential area, which was grouped into one of three regions (north, Kanto and Tohoku; central, Tokai and Hokuriku; or south, Kyushu and Chugoku) and also into three categories according to population size (city with population $\geq 1$ million, city with population $<1$ million, or town and village). Current smoking status (yes or no) was self-reported in the lifestyle questionnaire. Alcohol drinking (yes or no) and dietary supplement use (yes or no) were assessed as part of the DHQ. Physical activity was computed as average metabolic equivalent-hours per day [52] on the basis of the frequency and duration of five different activities over the preceding month, as reported in the lifestyle questionnaire.

\section{Statistical analysis}

All statistical analyses were performed with SAS statistical software, version 9.2 (SAS Institute Inc., Cary, NC, USA). All reported $P$ values are two-tailed, with a $P$ value of $<0.05$ considered statistically significant. Dietary TAC intakes were adjusted for energy by the residual method using a regression model [53]. The percentage contribution of each individual food item to dietary TAC was calculated by dividing the TAC from each individual food item by the daily individual dietary TAC.

Significant differences between participants with normal and elevated CRP concentrations (cutoff $1.0 \mathrm{mg} / \mathrm{mL}$ ) were assessed using Mann-Whitney signed-rank test or chisquare test. We used the non-parametric test because the result of Shapiro-Wilk's W test for normality showed that all continuous variables had non-normal distribution. Associations with elevated serum CRP concentration were examined for energy-adjusted dietary TAC. Participants were divided into two categories according to the median value of dietary TAC. Odds ratios (ORs) and 95\% confidence intervals (CIs) for elevated serum CRP concentrations were calculated after multivariate adjustment for potential confounding factors, including residential region, size of residential area, current smoking, alcohol drinking, dietary supplement use, physical activity (continuous), and BMI (continuous). Additionally, we adjusted for n-3 PUFA intake (energy-adjusted by residual method, continuous) because $n-3$ PUFA was the only dietary variable significantly associated with CRP; the following dietary variables were not associated with CRP: total fat, saturated fatty acids, monounsaturated fatty acids, polyunsaturated fatty acids, eicosapentaenoic acid + docosahexaenoic acid, alpha-linolenic acid, total dietary fiber, magnesium, vitamin $\mathrm{C}$, fruit, vegetables, fish and shellfish, and dietary glycemic load [5]. Spearman's correlation coefficients of each TAC and n-3 PUFA were 0.17 for FRAP, 0.17 for ORAC, 0.14 for TEAC, and 0.12 for TRAP. In terms of trans fatty acid, one previous study has shown the positive association with CRP [54]. We, however, did not investigate the association with CRP in the previous study. Nevertheless, 
Table 2 Characteristics of 443 Japanese women aged 18-22 years categorized by normal or elevated (cutoff $1 \mathrm{mg} / \mathrm{L}$ ) serum CRP concentration*

\begin{tabular}{|c|c|c|c|c|}
\hline & $\begin{array}{c}\text { Total } \\
(n=443)\end{array}$ & $\begin{array}{c}\text { Normal CRP } \\
\text { (CRP }<1 \mathrm{mg} / \mathrm{L}) \\
(\mathrm{n}=418)\end{array}$ & $\begin{array}{c}\text { Elevated CRP } \\
\text { (CRP } \geq 1 \mathrm{mg} / \mathrm{L}) \\
(\mathrm{n}=25)\end{array}$ & $P+$ \\
\hline Serum CRP concentration (mg/L) & $0.11(0.06-0.23)$ & $0.11(0.06-0.20)$ & $1.78(1.29-3.06)$ & \\
\hline Age (years) & $19(19-20)$ & $19(19-20)$ & $19(19-20)$ & 0.72 \\
\hline Body mass index $\left(\mathrm{kg} / \mathrm{m}^{2}\right)$ & $21.0(19.5-22.5)$ & $21.0(19.5-22.6)$ & $21.7(19.3-22.2)$ & 0.99 \\
\hline Residential region & & & & 0.37 \\
\hline North (Kanto and Tohoku) & $268(60.5)$ & $250(59.8)$ & $18(72.0)$ & \\
\hline Central (Tokai and Hokuriku) & $73(16.5)$ & $69(16.5)$ & $4(16.0)$ & \\
\hline South (Kyushu and Chugoku) & $102(23.0)$ & $99(23.7)$ & $3(12.0)$ & \\
\hline Size of residential area & & & & 0.75 \\
\hline City with population $\geq 1$ million & $77(17.4)$ & $74(17.7)$ & $3(12.0)$ & \\
\hline City with population $<1$ million & $329(74.3)$ & 309 (73.9) & $20(80.0)$ & \\
\hline Town and village & $37(8.4)$ & $35(8.4)$ & $2(8.0)$ & \\
\hline Current smoking & & & & 0.86 \\
\hline No & $428(96.6)$ & $404(96.7)$ & $24(96.0)$ & \\
\hline Yes & $15(3.5)$ & $14(3.4)$ & $1(4.0)$ & \\
\hline Alcohol drinking & & & & 0.10 \\
\hline No & $248(56.0)$ & $230(55.0)$ & $18(72.0)$ & \\
\hline Yes & $195(44.0)$ & $188(45.0)$ & $7(28.0)$ & \\
\hline Dietary supplement use & & & & 0.33 \\
\hline No & 357 (80.6) & $335(80.1)$ & $22(88.0)$ & \\
\hline Yes & $86(19.4)$ & $83(19.9)$ & $3(12.0)$ & \\
\hline Physical activity (total metabolic equivalents-hours/d) & $33.2(32.2-34.5)$ & $33.2(32.2-34.4)$ & $33.3(32.4-34.6)$ & 0.57 \\
\hline Energy intake (kcal/d) & $1718(1475-1986)$ & $1717(1476-1976)$ & 1795 (1347-1994) & 0.99 \\
\hline Total n-3 PUFA intake $(\mathrm{g} / \mathrm{d}) \neq$ & $2.2(1.9-2.6)$ & $2.2(1.9-2.6)$ & $2.2(1.9-2.6)$ & 0.50 \\
\hline \multicolumn{5}{|l|}{ Dietary TAC $\neq$} \\
\hline $\operatorname{FRAP}\left(\mathrm{mmol} \mathrm{Fe} e^{2+} / \mathrm{d}\right)$ & $10.61(7.42-16.06)$ & $10.79(7.55-16.33)$ & $7.65(5.47-11.68)$ & 0.004 \\
\hline ORAC (mmol TE/d) & $16.78(12.43-24.12)$ & $17.30(12.93-24.63)$ & $13.00(9.38-16.93)$ & 0.003 \\
\hline TEAC (mmol TE/d) & $6.26(4.67-8.83)$ & $6.45(4.73-8.92)$ & $5.32(3.66-6.01)$ & 0.01 \\
\hline TRAP (mmol TE/d) & $6.71(4.34-10.24)$ & $6.85(4.50-10.48)$ & $4.47(3.60-6.48)$ & 0.01 \\
\hline
\end{tabular}

CRP C-reactive protein, PUFA polyunsaturated fatty acid, TAC total antioxidant capacity, FRAP ferric reducing ability of plasma, ORAC oxygen radical absorbance capacity, TEAC Trolox equivalent antioxidant capacity, TRAP total radical-trapping antioxidant parameter, TE Trolox equivalent.

* Values are medians (interquartile ranges) or numbers of subjects (\%).

t $P$ value between normal CRP and elevated CRP groups. For continuous values, the Mann-Whitney signed-rank test was used; for categorical values, the chisquare test was used.

‡ Energy adjustment was performed according to the residual method.

while the major food contributors to trans fatty acid are fat and oil, bakery, confections, milk and milk products, and meat and meat products in young Japanese women (86\%) [55], these foods seldom contributed to TAC as shown below (1-4\%). Thus, it is unlikely that trans fatty acid and TAC are strongly correlated, neither does trans fatty acid confound or modify the association between TAC and CRP. We thus did not consider trans fatty acid in the present study.

\section{Results}

Subject characteristics by normal and elevated CRP concentration are shown in Table 2. Median serum CRP concentration was $0.113 \mathrm{mg} / \mathrm{L}$, with a range of 0.025 to $7.100 \mathrm{mg} / \mathrm{L}$. The prevalence of elevated CRP concentration was $5.6 \%$. Median dietary TAC was $10.61 \mathrm{mmol} \mathrm{Fe}{ }^{2+} / \mathrm{d}$ for FRAP, $16.78 \mathrm{mmol} \mathrm{TE} / \mathrm{d}$ for ORAC, $6.26 \mathrm{mmol} \mathrm{TE} / \mathrm{d}$ for TEAC, and $6.71 \mathrm{mmol} \mathrm{TE} / \mathrm{d}$ for TRAP. The range of Spearman's correlation coefficients between each dietary 
Table 3 Odds ratio and $95 \%$ confidence intervals for elevated (cutoff $1 \mathrm{mg} / \mathrm{L}$ ) serum CRP concentrations by low or high dietary TAC groups in 443 Japanese women aged 18-22 years

\begin{tabular}{|c|c|c|}
\hline & \multicolumn{2}{|c|}{ Category of dietary TAC } \\
\hline & Low $(n=221)$ & High $(n=222)$ \\
\hline $\operatorname{FRAP}\left(\mathrm{mmol} \mathrm{Fe} \mathrm{F}^{2+} / \mathrm{d}\right)^{*} \dagger$ & $7.41(0.71-10.60)$ & $16.03(10.61-37.17)$ \\
\hline n (\%) with elevated CRP & $18(8.1)$ & $7(3.2)$ \\
\hline Crude model & 1 (ref) & $0.37(0.15-0.90)$ \\
\hline Multivariate modelł & 1 (ref) & $0.39(0.16-0.98)$ \\
\hline ORAC $(\mathrm{mmol} T \mathrm{TE} / \mathrm{d})^{*}+$ & $12.43(1.18-16.73)$ & $24.13(16.78-50.77)$ \\
\hline n (\%) with elevated CRP & $17(7.7)$ & $8(3.6)$ \\
\hline Crude model & 1 (ref) & $0.45(0.19-1.06)$ \\
\hline Multivariate model $\neq$ & 1 (ref) & $0.48(0.20-1.14)$ \\
\hline TEAC $(\mathrm{mmol}$ TE/d)*† & $4.67(0.44-6.25)$ & $8.83(6.26-31.75)$ \\
\hline n (\%) with elevated CRP & $19(8.6)$ & $6(2.7)$ \\
\hline Crude model & 1 (ref) & $0.30(0.12-0.75)$ \\
\hline Multivariate modelł & 1 (ref) & $0.32(0.12-0.82)$ \\
\hline TRAP $\left(\mathrm{mmol}\right.$ TE/d)* ${ }^{*} \dagger$ & $4.34(0.31-6.66)$ & $10.23(6.71-52.42)$ \\
\hline n (\%) with elevated CRP & $19(8.6)$ & $6(2.7)$ \\
\hline Crude model & 1 (ref) & $0.30(0.12-0.75)$ \\
\hline Multivariate model $\neq$ & 1 (ref) & $0.31(0.12-0.81)$ \\
\hline
\end{tabular}

CRP C-reactive protein, TAC total antioxidant capacity, FRAP ferric reducing ability of plasma, ORAC oxygen radical absorbance capacity, TEAC Trolox equivalent antioxidant capacity, TRAP total radical-trapping antioxidant parameter, TE Trolox equivalent; ref, reference.

* Values are medians (ranges).

† Energy adjustment was performed according to the residual method.

₹ Adjusted for residential region [north (Kanto and Tohoku), central (Tokai and Hokuriku), and south (Kyushu and Chugoku)], size of residential area (city with a population $\geq 1$ million, city with a population $<1$ million, and town and village), current smoking (yes or no), alcohol drinking (yes or no), dietary supplement use (yes or no), physical activity level (total metabolic

equivalents-hours/d, continuous), body mass index ( $\mathrm{kg} / \mathrm{m}^{2}$, continuous), and $\mathrm{n}$ 3 polyunsaturated fatty acid intake ( $\mathrm{g} / \mathrm{d}$, energy-adjusted, continuous).

TAC was 0.89-0.98 (data not shown). For the contribution of each food item to dietary TAC (Table 1), green, barley, and oolong tea was the major contributor (FRAP, 57\%; ORAC, 47\%; TEAC, 37\%; and TRAP, 46\%) and coffee was the second major contributor (FRAP, 3\%; ORAC, 3\%; TEAC, 6\%; and TRAP, 10\%) in all four assays. At food group level, non-alcoholic beverages, including green, barley, and oolong tea and coffee, was the major contributor in all food groups. Although vegetables was the second contributor in the food groups (FRAP, 8\%; ORAC, 11\%; TEAC, 9\%; TRAP, 8\%), it contributed less than single food item of green, barley, and oolong tea. The only significant difference between the elevated and normal CRP concentration groups was seen for dietary TAC (Table 2), with respective ratios for each dietary TAC of only $65-82 \%$ of those of the normal CRP concentration group.

Table 3 shows the association between dietary TAC and elevated serum CRP concentration. The percentages of participants with elevated CRP levels in the low dietary TAC group (7.7-8.6\%) were about two to three times higher than those in the high dietary TAC group (2.7-3.6\%). ORs for elevated serum CRP concentration in the high versus low dietary TAC group were $0.30-0.45$ in the crude model, and were hardly changed after adjustment for possible confounders. TAC from FRAP was inversely associated with serum CRP concentration (adjusted OR for elevated CRP concentration in high versus low dietary TAC group: 0.39 [95\% CI: 0.16-0.98]; $P=0.04)$. With regard to TAC from ORAC, the inverse association between dietary TAC and serum CRP concentration was also observed with this method (adjusted OR: 0.48 [95\% CI: $0.20-1.14] ; P=0.10$ ), although the association did not reach statistical significance. TAC from TEAC was inversely associated with serum CRP concentration (adjusted OR: 0.32 [95\% CI: 0.12-0.82]; $P=0.02$ ). Additionally, TAC from TRAP was also inversely associated with serum CRP concentration (adjusted OR: 0.31 [95\% CI: 0.12-0.81]; $P=0.02$ ).

\section{Discussion}

In this study, we found that a higher dietary TAC was associated with a lower prevalence of elevated CRP concentration among young Japanese women. Dietary TAC from FRAP, TEAC, and TRAP were significantly inversely associated with serum CRP concentration. Dietary TAC from ORAC also showed an inverse association with serum CRP. The dietary TAC values of elevated serum CRP concentration group were significantly lower than those of normal CRP group. To our knowledge, this is the first study to examine the association between dietary TAC and elevated CRP concentration in a non-western population.

In the present study, dietary TAC was estimated using a DHQ for the four different assays of FRAP, ORAC, TEAC, and TRAP. The TRAP databases $[15,33]$ contain the TAC values of only a limited number of foods, and those of 38 foods could not be obtained. In contrast, the FRAP databases [29-32] contain an extensive number of foods, and values could not be obtained for only 16 foods. Further, most foods in the FRAP assay were assigned an analytical rather than a substituted or calculated TAC value. These different results were probably due to the different antioxidant mechanisms derived from different substrates, reaction conditions, and quantification methods [56]. Nevertheless, the major sources of dietary TAC were the same among the TAC assays and the TAC values of these food items were available in the literature (i.e., teas, coffee, and chocolate). Our study showed that dietary TAC from FRAP, TEAC, and TRAP were significantly inversely associated with serum CRP concentration. Dietary TAC from ORAC also showed an inverse association with serum CRP, albeit without 
statistical significance. Additionally, the correlation coefficients between respective dietary TAC values were high. These results may suggest that dietary TAC was inversely associated with serum CRP concentration regardless of assay.

Whereas previous western studies showed that the main contributors of dietary TAC were coffee, fruits, vegetables, and alcohol beverages [57-60], the major contributor in this present young Japanese population was green, barley, and oolong tea. Even the sum contributions of all vegetables or fruits were less than the contribution of single green, barley, and oolong tea. Additionally, vegetables commonly consumed in Japan differ from those in Italy $[14,15]$, and fruit and vegetable items consumed by contemporary young Japanese women differ from those by young Spanish adults [12]. Nevertheless, dietary TAC was inversely associated with CRP in our Japanese population, as with Italian and Spanish populations $[10,12]$, suggesting that a high dietary TAC is important for a low prevalence of elevated CRP level regardless of the type or origin of food. The present finding of a significant association between dietary TAC and CRP contrasts with a previous study in the same population which found no association between single intakes of vitamin $C$, fruits, and vegetables and serum CRP [5]. This difference in turn suggests that complex combinations of antioxidant nutrients and foods might be more strongly associated with CRP than any single nutrient or food alone.

Dietary TAC was significantly associated with some lipid biomarkers (e.g., oxidized low-density lipoprotein; ox-LDL) and plasma TAC was negatively correlated with ox-LDL concentrations [61]. These results may suggest that high consumption of antioxidant-rich foods decrease oxidation in the low-density lipoprotein by increasing the plasma TAC availability. These favorable situations might relate to low serum CRP concentrations. CRP production in the liver is induced by interleukin-6 (IL-6) [1,62]. Adipocytes produce many inflammatory cytokines, including IL-6, and their transcription is regulated by the nuclear transcription factor$\kappa \mathrm{B}(\mathrm{NF}-\mathrm{\kappa B})[62,63]$. Given previous findings that dietary TAC was inversely associated with CRP as well as with mRNA expression of NF- $\kappa$ B subunit- 1 and IL- 6 in young Spanish adults [12] and that ox-LDL is able to induce a pro-inflammatory status by the activation of NF- $\mathrm{kB}$ [61], the association between dietary TAC and CRP might accordingly relate to NF- $\mathrm{kB}$-regulated pathways interacting ox-LDL. However, that study also showed that dietary TAC was not associated with serum IL-6 concentration [12]. Meanwhile, another study reported that dietary TAC tended to show an inverse association with IL-6 level [11]. These inconsistent results hamper any comprehensive understanding of the mechanism of the relationship between lower CRP concentrations and dietary TAC. Various antioxidants contribute to dietary TAC and these compounds regulate inflammation via multiple signaling pathways [64]. The mechanism by which dietary TAC associates with serum CRP concentration is therefore likely complex. Further, the validity of TAC as a measure of functional efficacy of antioxidant defense in vivo was questioned. In fact, not only dietary phytochemicals, but also powerful enzymes in cells and tissues contribute to the prevention of oxidation. Additionally, antioxidant capacity of some molecules in foods may change into the uptake and metabolism [65]. We should take into account the fact that dietary TAC may not necessarily reflect antioxidant level in vivo.

Several limitations of the present study should be mentioned. First, because TAC data on Japanese foods were available from only a single database [14], dietary TAC was estimated using databases developed in other countries. Additionally, many foods were assigned a substituted or calculated TAC value. Further, because a reliable TAC database for dietary supplements could not be obtained, we did not consider the intake of dietary supplements in calculating dietary TAC. Second, the DHQ was not specifically designed to measure dietary TAC. In assessing dietary TAC, we were unable to investigate the validity of the DHQ against the 16-day dietary records we previously used to investigate the validity of other dietary variables $[20,21]$ because the dietary record contained an insufficient number of foods with information on TAC values $(n=143-373)$. However, a previous validation study among 92 adult women reported Pearson correlation coefficients of 0.64 for $\beta$-carotene, 0.52 for vitamin $C$, and 0.47 for $\alpha$-tocopherol [21], and Spearman correlation coefficients for food groups were 0.75 for coffee, 0.59 for green and oolong tea, 0.56 for total vegetables, and 0.40 for fruits [20]. This satisfactory validity of the DHQ for a wide range of antioxidant nutrients and foods provides some reassurance. Third, participants of the present study were selected female dietetic students, not a random sample of Japanese women. In addition, because of our recruitment procedure, the exact response rate was unknown, which might have produced recruitment bias. Thus, our results cannot easily be extrapolated to the general Japanese population. Fourth, although we attempted to adjust for a wide range of potential confounding variables, we are unable to rule out residual confounding. Finally, the cross-sectional nature of the study hampers the drawing of any conclusions on causal inferences among dietary TAC and serum CRP concentration.

\section{Conclusion}

This study showed that dietary TAC was inversely associated with serum CRP concentration among young 
Japanese women regardless of assay. This result will provide valuable insights from a preventive perspective. Our result should be confirmed in other Asian and Japanese populations.

\section{Abbreviations \\ TAC: Total antioxidant capacity; CRP: C-reactive protein; DHQ: Diet history questionnaire; PUFA: Polyunsaturated fatty acid; FRAP: Ferric reducing ability of plasma; ORAC: Oxygen radical absorbance capacity; TEAC: Trolox equivalent antioxidant capacity; TRAP: Total radical-trapping antioxidant parameter; TE: Trolox equivalent; BMI: Body mass index; OR: Odds ratio; Cl: Confidence interval; IL-6: Interleukin-6; NF-KB: Nuclear transcription factor-kB.}

\section{Competing interests}

The authors declare that they have no competing interests.

\section{Authors' contribution}

SK formulated the hypothesis, analyzed and interpreted the data, and wrote the manuscript. KM contributed to the concept and design of the study, the study protocol, and data collection and management; coordinated the field work; interpreted the data; and contributed to the writing and editing of the manuscript. SS was responsible for the concept and design of the study, the study protocol, and data collection and management; and contributed to the writing and editing of the manuscript. KU contributed to the concept and design of the study, the study protocol, and data collection. MY, HH, TG, $\mathrm{JO}, \mathrm{KB}, \mathrm{KO}, \mathrm{TK}, \mathrm{RW}$, and YS contributed to data collection. All authors contributed to the final version of the manuscript. All authors read and approved the final manuscript.

\section{Acknowledgments}

This study was supported by grants from the Ministry of Health, Labor, and Welfare of Japan.

\section{Author details}

'Department of Social and Preventive Epidemiology, Graduate School of Medicine, the University of Tokyo, Tokyo, Japan. ${ }^{2}$ Department of Social and Preventive Epidemiology, School of Public Health, the University of Tokyo, 7-3-1 Hongo, Bunkyo-ku, Tokyo 113-0033, Japan. ${ }^{3}$ Laboratory of Physiological Nutrition, Kagawa Nutrition University, Saitama, Japan. ${ }^{4}$ Department of Health and Nutrition Science, Faculty of Health and Social Welfare Science, Nishikyushu University, Saga, Japan. ${ }^{5}$ Department of Human Environmental Science, Fukuoka Women's University, Fukuoka, Japan. ${ }^{6}$ Department of Nutrition, School of Food and Nutritional Sciences, University of Shizuoka, Shizuoka, Japan. ${ }^{7}$ Department of Nutrition, Faculty of Home Economics, Tokyo Kasei University, Tokyo, Japan. ${ }^{8}$ Department of Kids Culture Design Center, Mie Chukyo University, Mie, Japan. ${ }^{9}$ Graduate School of Science for Living System, Showa Women's University, Tokyo, Japan. ${ }^{10}$ Department of Health and Nutrition, University of Niigata Prefecture, Niigata, Japan.

${ }^{11}$ Department of Nutrition Management, Faculty of Health and Nutrition, Minami Kyushu University, Miyazaki, Japan.

\section{Received: 8 May 2012 Accepted: 16 October 2012}

Published: 30 October 2012

\section{References}

1. Pepys MB, Hirschfield GM: C-reactive protein: a critical update. J Clin Invest 2003, 11:1805-1812

2. Nanri A, Moore MA, Kono S: Impact of C-reactive protein on disease risk and its relation to dietary factors. Asian Pac J Cancer Prev 2007, 8:167-177.

3. Floegel A, Chung SJ, von Ruesten A, Yang M, Chung CE, Song WO, Koo SI Pischon T, Chun OK: Antioxidant intake from diet and supplements and elevated serum C-reactive protein and plasma homocysteine concentrations in US adults: a cross-sectional study. Public Health Nutr 2011, 14:2055-2064.

4. Neyestani TR, Shariatzade N, Kalayi A, Gharavi A, Khalaji N, Dadkhah M, Zowghi T, Haidari H, Shab bidar S: Regular daily intake of black tea improves oxidative stress biomarkers and decreases serum C-reactive protein levels in type 2 diabetic patients. Ann Nutr Metab 2010, 57:40-49.
5. Murakami K, Sasaki S, Takahashi Y, Uenishi K, Yamasaki M, Hayabuchi H, Goda T, Oka J, Baba K, Ohki K, Muramatsu K, Sugiyama Y: Total n-3 polyunsaturated fatty acid intake is inversely associated with serum C-reactive protein in young Japanese women. Nutr Res 2008, 28:309-314.

6. Maki T, Pham NM, Yoshida D, Yin G, Ohnaka K, Takayanagi R, Kono S: The relationship of coffee and green tea consumption with high-sensitivity C-reactive protein in Japanese men and women. Clin Chem Lab Med 2010, 48:849-854.

7. de Oliveira Otto MC, Alonso A, Lee DH, Delclos GL, Jenny NS, Jiang R, Lima JA, Symanski E, Jacobs DR Jr, Nettleton JA: Dietary micronutrient intakes are associated with markers of inflammation but not with markers of subclinical atherosclerosis. J Nutr 2011, 141:1508-1515.

8. Stanner SA, Hughes J, Kelly CN, Buttriss J: A review of the epidemiological evidence for the 'antioxidant hypothesis'. Public Health Nutr 2004, 7:407-422.

9. Serafini M, Bellocco R, Wolk A, Ekstrom AM: Total antioxidant potential of fruit and vegetables and risk of gastric cancer. Gastroenterology 2002, 123:985-991.

10. Brighenti F, Valtuena S, Pellegrini N, Ardigo D, Del Rio D, Salvatore S, Piatti P, Serafini M, Zavaroni I: Total antioxidant capacity of the diet is inversely and independently related to plasma concentration of high-sensitivity C-reactive protein in adult Italian subjects. Br J Nutr 2005, 93:619-625.

11. Detopoulou P, Panagiotakos DB, Chrysohoou C, Fragopoulou E, Nomikos T, Antonopoulou S, Pitsavos C, Stefanadis C: Dietary antioxidant capacity and concentration of adiponectin in apparently healthy adults: the ATTICA study. Eur J Clin Nutr 2010, 64:161-168.

12. Hermsdorff HH, Zulet MA, Puchau B, Martinez JA: Fruit and vegetable consumption and proinflammatory gene expression from peripheral blood mononuclear cells in young adults: a translational study. Nutr Metab (Lond) 2010, 7:42.

13. Valtuena S, Pellegrini N, Franzini L, Bianchi MA, Ardigo D, Del Rio D, Piatti $P$, Scazzina F, Zavaroni I, Brighenti F: Food selection based on total antioxidant capacity can modify antioxidant intake, systemic inflammation, and liver function without altering markers of oxidative stress. Am J Clin Nutr 2008, 87:1290-1297.

14. Takebayashi J, Oki T, Chen J, Sato M, Matsumoto T, Taku K, Tsubota Utsugi $M$, Watanabe J, Ishimi Y: Estimated average daily intake of antioxidants from typical vegetables consumed in Japan: a preliminary study. Biosci Biotechnol Biochem 2010, 74:2137-2140.

15. Pellegrini N, Serafini M, Colombi B, Del Rio D, Salvatore S, Bianchi M, Brighenti F: Total antioxidant capacity of plant foods, beverages and oils consumed in Italy assessed by three different in vitro assays. J Nutr 2003, 133:2812-2819.

16. Wener MH, Daum PR, McQuillan GM: The influence of age, sex, and race on the upper reference limit of serum C-reactive protein concentration. J Rheumatol 2000, 27:2351-2359.

17. Pearson TA, Mensah GA, Alexander RW, Anderson JL, Cannon RO 3rd, Criqui M, Fadl YY, Fortmann SP, Hong Y, Myers GL, Rifai N, Smith SC Jr, Taubert K, Tracy RP, Vinicor F: Markers of inflammation and cardiovascular disease: application to clinical and public health practice: A statement for healthcare professionals from the Centers for Disease Control and Prevention and the American Heart Association. Circulation 2003, 107:499-511.

18. Ministry of Health and Welfare: Recommended dietary allowance for Japanese: dietary reference intakes 6 th ed. Tokyo: Ministry of Health and Walfare; 1999 (in Japanese).

19. Okubo H, Sasaki S, Murakami K, Kim MK, Takahashi Y, Hosoi Y, Itabashi M: Three major dietary patterns are all independently related to the risk of obesity among 3760 Japanese women aged $18-20$ years. Int J Obes (Lond) 2008, 32:541-549.

20. Kobayashi S, Murakami K, Sasaki S, Okubo H, Hirota N, Notsu A, Fukui M, Date C: Comparison of relative validity of food group intakes estimated by comprehensive and brief-type self-administered diet history questionnaires against $16 \mathrm{~d}$ dietary records in Japanese adults. Public Health Nutr 2011, 4:1200-1211.

21. Kobayashi S, Honda S, Murakami K, Sasaki S, Okubo H, Hirota N, Notsu A, Fukui M, Date C: Both comprehensive and brief self-administered diet history questionnaires satisfactorily rank nutrient intakes in Japanese adults. J Epidemiol 2012, 22:151-159.

22. Science and Technology Agency: Standard tables of food composition in Japan, 2010. Tokyo: Ministry of Education, Culture, Sports, Science and Technology; 2010. in Japanese. 
23. Isabelle M, Lee BL, Lim MT, Koh WP, Huang J, Ong CN: Antioxidant activity and profiles of common vegetables in Singapore. Food Chem 2010, 120:993-1003

24. Isabelle M, Lee BL, Lim MT, Koh WP, Huang J, Ong CN: Antioxidant activity and profiles of common fruits in Singapore. Food Chem 2010, 123:77-84.

25. Lako J, Trenerry VC, Wahlqvist M, Wattanapenpaiboon N, Sotheeswaran S, Premier R: Phytochemical flavonols, carotenoids and the antioxidant properties of a wide selection of Fijian fruit, vegetables and other readily available foods. Food Chem 2007, 101:1727-1741.

26. Fernandez Orozco R, Frias J, Zielinski H, Piskula MK, Kozlowska H, Vidal Valverde C: Kinetic study of the antioxidant compounds and antioxidant capacity during germination of Vigna radiata cv. emmerald, Glycine max cv. jutro and Glycine max cv. merit. Food Chem 2008, 111:622-630.

27. Doblado R, Frias J, Vidal-Valverde C: Changes in vitamin C content and antioxidant capacity of raw and germinated cowpea (Vigna sinensis var. carilla) seeds induced by high pressure treatment. Food Chem 2007, 101:918-923.

28. Garcia Alonso M, Pascual Teresa S, Santos Buelga C, Rivas Gonzalo JC: Evaluation of the antioxidant properties of fruits. Food Chem 2004 84:13-18.

29. Carlsen MH, Halvorsen BL, Holte K, Bohn SK, Dragland S, Sampson L, Willey C, Senoo H, Umezono Y, Sanada C, Barikmo IE, Berhe N, Willett WC, Phillips KM, Jacobs DR Jr, Blomhoff R: The total antioxidant content of more than 3100 foods, beverages, spices, herbs and supplements used worldwide. Nutr J 2010, 9:3.

30. Halvorsen BL, Carlsen MH, Phillips KM, Bohn SK, Holte K, Jacobs DR Jr, Blomhoff R: Content of redox-active compounds (ie, antioxidants) in foods consumed in the United States. Am J Clin Nutr 2006, 84:95-135.

31. Halvorsen BL, Holte K, Myhrstad MC, Barikmo I, Hvattum E, Remberg SF, Wold AB, Haffner K, Baugerod H, Andersen LF, Moskaug O, Blomhoff R: A systematic screening of total antioxidants in dietary plants. J Nutr 2002, 132:461-471

32. Dragland S, Senoo H, Wake K, Holte K, Blomhoff R: Several culinary and medicinal herbs are important sources of dietary antioxidants. J Nutr 2003, 133:1286-1290.

33. Pellegrini N, Serafini M, Salvatore S, Del Rio D, Bianchi M, Brighenti F: Total antioxidant capacity of spices, dried fruits, nuts, pulses, cereals and sweets consumed in Italy assessed by three different in vitro assays. Mol Nutr Food Res 2006, 50:1030-1038.

34. Park YS, Towantakavanit K, Namiesnik J, Sliwka Kaszynska M, Kusznierewicz B, Kozlowska Tylingo K, Leontowicz H, Leontowicz M, Matrinez Ayala AL, Gorinstein S: Partial characterization of three Korean white lotus cultivars. J Agric Food Chem 2009, 57:4391-4397.

35. U.S. Department of Agriculture, Agricultural Research Service: USDA database for the oxygen radical absorbance capacity (ORAC) of selected foods, release 2. Maryland: Nutrient Data Laboratory; 2010

36. Cao G, Sofic E, Proir RL: Antioxidant capacity of tea and common vegetables. J Agric Food Chem 1996, 44:3426-3431

37. Wang H, Cao G, Proir RL: Total antioxidant capacity of fruits. J Agric Food Chem 1996, 44:701-705.

38. Sanchez Moreno C, Cao G, Ou B, Prior RL: Anthocyanin and proanthocyanidin content in selected white and red wines. Oxygen radical absorbance capacity comparison with nontraditional wines obtained from highbush blueberry. J Food Compos Anal 2003, 51:4889-4896.

39. Bellido GG, Beta T: Anthocyanin composition and oxygen radica scavenging capacity (ORAC) of milled and pearled purple, black, and common barley. J Agric Food Chem 2009, 57:1022-1028.

40. Zielinski H, Michalska A, Amigo Benavent M, del Castillo MD, Piskula MK: Changes in protein quality and antioxidant properties of buckwheat seeds and groats induced by roasting. J Agric Food Chem 2009, 57:4771-4776.

41. Rechner AR, Wagner E, Van Buren L, Van De Put F, Wiseman S, Rice Evans CA: Black tea represents a major source of dietary phenolics among regular tea drinkers. Free Radic Res 2002, 36:1127-1135.

42. Henning SM, Fajardo Lira C, Lee HW, Youssefian AA, Go VL, Heber D: Catechin content of 18 teas and a green tea extract supplement correlates with the antioxidant capacity. Nutr Cancer 2003, 45:226-235.

43. Chandra S, De Mejia Gonzalez E: Polyphenolic compounds, antioxidant capacity, and quinone reductase activity of an aqueous extract of Ardisia compressa in comparison to mate (llex paraguariensis) and green (Camellia sinensis) teas. J Agric Food Chem 2004, 52:3583-3589.
44. Rufian Henares JA, Morales FJ: Effect of in vitro enzymatic digestion on antioxidant activity of coffee melanoidins and fractions. J Agric Food Chem 2007, 55:10016-10021.

45. Mullen W, Nemzer B, Ou B, Stalmach A, Hunter J, Clifford MN, Combet E: The antioxidant and chlorogenic acid profiles of whole coffee fruits are influenced by the extraction procedures. J Agric Food Chem 2011, 59:3754-3762

46. Ferracane R, Graziani G, Gallo M, Fogliano V, Ritieni A: Metabolic profile of the bioactive compounds of burdock (Arctium lappa) seeds, roots and leaves. J Pharm Biomed Anal 2010, 51:399-404.

47. Chandrasekara N, Shahidi F: Effect of roasting on phenolic content and antioxidant activities of whole cashew nuts, kernels, and testa. J Agric Food Chem 2011, 59:5006-5014.

48. Corral Aguayo RD, Yahia EM, Carrillo Lopez A, Gonzalez Aguilar G: Correlation between some nutritional components and the total antioxidant capacity measured with six different assays in eight horticultural crops. J Agric Food Chem 2008, 56:10498-10504.

49. Onofrejova L, Vasickova J, Klejdus B, Stratil P, Misurcova L, Kracmar S, Kopecky J, Vacek J: Bioactive phenols in algae: the application of pressurized-liquid and solid-phase extraction techniques. J Pharm Biomed Anal 2010, 51:464-470.

50. Niu K, Hozawa A, Guo H, Kuriyama S, Ebihara S, Yang G, Ohmori Matsuda K, Nakaya N, Takahashi H, Fujita K, Wen S, Arai H, Tsuji I, Nagatomi R: Serum C-reactive protein even at very low $(<1.0 \mathrm{mg} / \mathrm{l})$ concentration is associated with physical performance in a community-based elderly population aged 70 years and over. Gerontology 2008, 54:260-267.

51. Niu K, Hozawa A, Kuriyama S, Ohmori Matsuda K, Shimazu T, Nakaya N, Fujita K, Tsuji I, Nagatomi R: Dietary long-chain n-3 fatty acids of marine origin and serum C-reactive protein concentrations are associated in a population with a diet rich in marine products. Am J Clin Nutr 2006, 84:223-229.

52. Ainsworth BE, Haskell WL, Leon AS, Jacobs DR Jr, Montoye HJ, Sallis JF, Paffenbarger RS Jr: Compendium of physical activities: classification of energy costs of human physical activities. Med Sci Sports Exerc 1993, 25:71-80.

53. Willett W, Stampfer MJ: Total energy intake: implications for epidemiologic analyses. Am J Epidemiol 1986, 24:17-27.

54. Lopez Garcia E, Schulze MB, Meigs JB, Manson JE, Rifai N, Stampfer MJ, Willett WC, Hu FB: Consumption of trans fatty acids is related to plasma biomarkers of inflammation and endothelial dysfunction. J Nutr 2005, 135:562-566.

55. Yamada M, Sasaki S, Murakami K, Takahashi Y, Uenishi K: Association of trans fatty acid intake with metabolic risk factors among free-living young Japanese women. Asia Pac J Clin Nutr 2009, 18:359-371.

56. Hollman PC, Cassidy A, Comte B, Heinonen M, Richelle M, Richling E, Serafini M, Scalbert A, Sies H, Vidry S: The biological relevance of direct antioxidant effects of polyphenols for cardiovascular health in humans is not established. J Nutr 2011, 141:989S-1009S.

57. Puchau B, Zulet MA, Gonzalez de Echavarri A, Hermsdorff HH, Martinez JA Dietary total antioxidant capacity is negatively associated with some metabolic syndrome features in healthy young adults. Nutrition 2010, 26:534-541

58. Rautiainen S, Serafini M, Morgenstern R, Prior RL, Wolk A: The validity and reproducibility of food-frequency questionnaire-based total antioxidant capacity estimates in Swedish women. Am J Clin Nutr 2008, 87:1247-1253.

59. Pellegrini N, Salvatore S, Valtuena S, Bedogni G, Porrini M, Pala V, Del Rio D, Sieri S, Miglio C, Krogh V, Zavaroni I, Brighenti F: Development and validation of a food frequency questionnaire for the assessment of dietary total antioxidant capacity. J Nutr 2007, 137:93-98.

60. di Giuseppe R, Arcari A, Serafini M, Di Castelnuovo A, Zito F, De Curtis A, Sieri S, Krogh V, Pellegrini N, Schunemann HJ, Donati MB, de Gaetano G, lacoviello L: Total dietary antioxidant capacity and lung function in an Italian population: a favorable role in premenopausal/never smoker women. Eur J Clin Nutr 2012, 66:61-68.

61. Hermsdorff HH, Puchau B, Volp AC, Barbosa KB, Bressan J, Zulet MA, Martinez JA: Dietary total antioxidant capacity is inversely related to central adiposity as well as to metabolic and oxidative stress markers in healthy young adults. Nutr Metab (Lond) 2011, 8:59.

62. Hajer GR, van Haeften TW, Visseren FL: Adipose tissue dysfunction in obesity, diabetes, and vascular diseases. Eur Heart J 2008, 29:2959-2971. 
63. Koh KK, Oh PC, Quon MJ: Does reversal of oxidative stress and inflammation provide vascular protection? Cardiovasc Res 2009, 81:649-659.

64. Pan MH, Lai CS, Dushenkov S, Ho CT: Modulation of inflammatory genes by natural dietary bioactive compounds. J Agric Food Chem 2009, 57:4467-4477.

65. Sies H: Total antioxidant capacity: appraisal of a concept. J Nutr 2007, 137:1493-1495.

doi:10.1186/1475-2891-11-91

Cite this article as: Kobayashi et al.: Dietary total antioxidant capacity

from different assays in relation to serum C-reactive protein among

young Japanese women. Nutrition Journal 2012 11:91.

\section{Submit your next manuscript to BioMed Central and take full advantage of:}

- Convenient online submission

- Thorough peer review

- No space constraints or color figure charges

- Immediate publication on acceptance

- Inclusion in PubMed, CAS, Scopus and Google Scholar

- Research which is freely available for redistribution 